CIC. Cuadernos de Información y Comunicación ISSN: 1135-7791

http://dx.doi.org/10.5209/CIYC.55980

\title{
Los mitos y su influencia en los mensajes publicitarios de los artículos de lujo
}

\author{
Ma del Mar Revilla Peña $^{1}$
}

Enviado: 25 de febrero de 2017 / Aceptado: 2 de marzo de 2017

Resumen. En este artículo quiero demostrar cómo la influencia de los mitos en los mensajes publicitarios es notoria. El consumo es una de las herramientas más importantes que reflejan el estado actual de la economía, siendo en este caso el consumo de los artículos de lujo el objeto de mi estudio. Por su naturaleza tan especial, los artículos de lujo, demuestran que en épocas de crisis saben capear el temporal mejor que el resto de productos, y es en este punto donde los publicistas recurren a mensajes que impactan más, para hacernos llegar que quien consume determinados productos de lujo va más allá de buscar un producto, busca experiencias, emociones... todas estas sensaciones se logran cuando el lujo está asociado a un mito, a una leyenda, a un ritual.

Palabras clave: Mito; publicidad; lujo; crisis; economía; globalización.

\section{[en] The myths and their influence on the publicity messages of the articles of luxury}

\begin{abstract}
In this article I want to show how the influence of myths in publicity messages is important. Consumption is one of the most important tools to reflect the current state of the economy, and particularly luxury items are going to be the subject of this study. Due to its special nature, luxury items manage the storm better than other items in economic crisis, and this is where advertisers use messages with more impact, to let us know that luxury items consumers are not only looking for a product, they go beyond looking for experiences, emotions, ... and all these sensations are achieved when luxury is associated with a myth, a legend, a ritual.
\end{abstract}

Keywords: Myth; publicity; luxury, crisis; economy; globalization.

Sumario. 1. Introducción. 2. La lógica del consumo. 3. El mito como recurso de la publicidad. 4. ¿Qué es el lujo? 5. Casos concretos de artículos de lujo que usan los mitos en sus campañas para impactar más en el mensaje. 6. La publicidad si sabe de crisis, pero ha sabido adaptarse gracias a la globalización. 7. Conclusiones. Bibliografía.

Cómo citar: Revilla Peña, Ma.M. (2017). Los mitos y su influencia en los mensajes publicitarios de los artículos de lujo, en CIC. Cuadernos de Información y Comunicación 22, 305-314.

\footnotetext{
1 Universidad Complutense de Madrid.

Email: mmrevi02@ucm.es
} 


\section{Introducción}

Tras superar varias crisis en los últimos años, nos hemos ido dando cuenta de muchas cosas. En la crisis del 29 se hizo evidente que era fundamental no sólo producir las mercancías, sino también fabricar las necesidades.

La crisis del 2007 ha hecho también que cambiemos las pautas del consumo, pensamos más en nuestras decisiones de consumo, tenemos mucha información.

La etapa presente, que puede calificarse de posmoderna, se basa en una sociedad de consumo, con carácter geográfico global, y con predominio de lo emotivo y lo personal.

Una de las consecuencias también de estos años, ha sido que los pobres son más pobres y los ricos más ricos, desapareciendo en gran medida las clases medias.

Y son este público, el de los ricos (aunque a veces se sacrifiquen para ello), por lógica, los que consumen artículos de lujo, artículos con glamour.

Los datos que tenemos demuestran que la industria del lujo no está en crisis, tampoco lo estuvo tras la crisis provocada por el 11-S, la neumonía asiática o la guerra de Irak, tal y como manifestó Giorgio Armani "los productos que desaparecen de las tiendas con más rapidez son los más caros". Según la Asociacion Luxury Spain, el sector del lujo facturó 4.800 millones de euros durante el 2012 en España, un 15\% más que el año anterior, a pesar de la crisis y del auge del low cost,( que también afecta al consumo de productos de lujo). En la última década los precios de los productos de lujo se han disparado casi un $60 \%$, pese a que en los últimos años hemos sufrido una de la crisis más duras de la historia. Según la firma Bain \& Company este sector no deja de crecer, en la eurozona contamos con 4 de los 10 mercados de bienes de lujo más grandes del mundo y España se encuentra entre ellos, siempre por detrás de Italia, Francia y Alemania.

Las compañías publicitarias aprovechan el efecto snob que buscan muchos clientes con la posesión de determinados productos. Es aquí, en este punto, donde intervienen los mitos, jugando un papel fundamental por el mensaje que ellos transmiten.

Los anuncios de las marcas de lujo si parecen reales y no te hacen soñar parecen no servir, es como el arte efímero, lo que no podemos tocar, ni siquiera sentir, pero si imaginar nos hace desearlo con mucha fuerza. Los anuncios reflejan el ADN de la marca, su esencia, sus valores más intrínsecos, lo que importa es el alma de la marca, la historia, el mito y la leyenda, así como la calidad y rareza del producto.

Además por otro lado la saturación de bienes materiales estereotipados ha forzado a imaginar otras fórmulas de exclusividad, que es donde el diseño, la publicidad tienen su papel principal como traductores de fórmulas de lujo.

\section{La lógica del consumo}

Muchos ciudadanos van a comprar los mismos objetos, vestirse del mismo modo, suspirar por el mismo automóvil, soñar con iguales vacaciones, exhibir un mismo estilo, pero siempre recibiendo la impresión de que cada uno de ellos está eligiendo libremente en el mercado, de qué está ejerciendo un soñado derecho, el de escoger entre Coca-Cola y Pepsi (Pérez Tornero, 1992). 
Los países desarrollados han sustentado su desarrollo en el último siglo gracias a la lógica del consumo. Para ello, la política, la economía y los medios de comunicación se pusieron de acuerdo: ya que había que fomentar el consumo, había que vincular consumo y felicidad y nos vendieron que la felicidad consiste en satisfacer nuestros deseos y necesidades y, para eso, pusieron en nuestras manos el sistema del consumo.

El sistema ha funcionado durante décadas y todavía hoy, en plena crisis sistémica (entendida como aquellas en la que se producen cambios profundos que afectan a la esencia del sistema), la única receta posible que nos venden los estudiosos es la de re-activar el consumo.

La lógica del actual sistema presupone que la felicidad es fruto de la satisfacción de necesidades, estamos satisfechos por nuestros logros, cuando alcanzamos los resultados esperados, cuando recibimos un salario justo.....cuando lo recibido se ajusta a nuestra demanda... cuando lo tenemos, ya no buscamos nada y nos aburrimos, necesitamos encontrar o inventar nuevas insatisfacciones que satisfacer.

Vemos que si la lógica del sistema que inventamos no es la lógica del verdadero desarrollo humano, algo termina por romperse, y buscamos buscamos...., siendo el lujo una de las formas de consumo, que parece dar sentido a nuestra vida.

Podemos pensar que el lujo es desmedida, derivación de la locura, pero incluso las necesidades normales, una vez satisfechas, se reinventan o se imitan al alza bajo la presión publicitaria, motor del consumo imparable. El modelo comienza por la necesidad, sigue por el exceso, y va hacia el agotamiento o hacia el límite, y en su recorrido genera desigualdades.

Como consumidores no sólo tomamos decisiones de compra que son enteramente lógicas, y es que como decía Eistein: "Sólo chocando con la razón podemos avanzar". Además los bienes de lujo, que es el caso que tratamos, proporcionan satisfacción a otro tipo de motivaciones como las aspiracionales y las emocionales. Por este motivo, el razonamiento lógico aislado no nos permitiría entender la esencia del lujo. Es como querer investigar el comportamiento humano sin preguntarse cómo funciona el componente racional.

Thorstein Veblen, un sociólogo a principios del siglo XX desarrolló la tesis del "derroche ostentible" y la "cultura pecuniaria", en la que la belleza de un objeto se mide en función de su precio, y el gasto ostentoso es una evidencia del éxito. Es decir que al hombre le satisface, tenga mucho o poco, despilfarrar y que se note. $\mathrm{Al}$ otro lado, Georg Simmel, sociólogo y filósofo alemán, defendió la sensatez humana ante, por ejemplo, la moda y afirmó:"Cuanto más rápido cambia, más deben bajar los precios", esta regla explicaría por qué la aceleración de los ciclos de moda ha provocado la democratización de las tendencias (esto es, la aparición de Zara) y el éxito del lujo: "No es que la gente adore derrochar, es simplemente que el lujo se ha popularizado".

\section{El mito como recurso de la publicidad}

El mito es un relato, un patrón narrativo, que pretende dar significado y sentido a nuestra existencia, es una forma de dar sentido a un mundo que en ocasiones no lo tiene, "el mito...expresa, fomenta y codifica la creencia; salvaguarda y refuerza la 
moral; garantiza la eficacia del ritual y contiene reglas prácticas por las que el hombre puede guiarse. Es pues un ingrediente vital de la civilización humana; no es un cuento inútil, sino una fuerza activa muy elaborada" (Malinowski; 1994:125).

Aunque el mito en un principio transmitía una historia sagrada, hoy podemos hablar de mito como un símbolo colectivo, fantasías colectivas, leyendas de héroes... literatura, cine y como no, la publicidad, son los vehículos del mito.

Uno de los problemas actuales de nuestra sociedad, es que actualmente está ausente de mitos, hoy como nunca el hombre necesita ritos que le permita encontrar significado a su existencia y a los objetos que le rodea.

Para identificar un producto hay que crear una marca o logotipo a través de las cuales se reconozca el producto. La marca es un símbolo complejo, es la suma intangible de los atributos de un producto, su historia, su reputación, es la percepción de los consumidores, de las personas que lo usan y sus propias experiencias. Los términos empleados (deseo, placer, arte, juego, amor...) son términos favoritos de la publicidad, autolegitimada siempre por su recurso al mito. Además hoy la publicidad usa el mito porque este habita en todo hombre y son los hombres los generadores de la publicidad, además de la conveniencia de manejar y mover los fondos de la inconsciencia del consumidor, allí donde reside el control no consciente de sus impulsos y se forman sus deseos y aspiraciones más profundas, también es generadora y creadora de nuevos mitos. Cualquier mito más allá de tiempos y culturas, universaliza lo humano.

La publicidad puede contemplarse como causa y efecto del estado general de la sociedad presente y como tal está al servicio de la imposición de valores y creación de los mismos. Como vemos la publicidad no escapa del influjo del mito y en el ejercicio de su poder lo ratifica y difunde mientras lo usa para propagarse con mayor eficacia. La publicidad no debe entenderse como algo aislado sino que absorbe como una esponja todo lo que está a su alrededor, es un lenguaje multidisciplinar donde se funde la literatura, las artes plásticas, la música, el cine... y los mitos no son una excepción.

Una de las claves del poder de la comunicación publicitaria se encuentra en que el mito ayuda a elaborar el mensaje de la publicidad, esto lo encontramos en numerosas empresas que utilizan en sus mensajes publicitarios relatos o discursos míticos para impactar más en el público, con el objetivo final de aumentar el consumo de sus productos o por lo menos de darlo a conocer.

Vemos por tanto como en la dimensión simbólica del mensaje publicitario nos encontramos frente al mito que participa de forma fundamental en la construcción del cuerpo simbólico del discurso de la publicidad.

Las estructuras míticas resultan persuasivas por varias razones. Por una parte, el mito responde a toda cuestión antes de ser planteada, impide que se planteen la cuestión (Gusdorf cit. en Fernández y Pineda). Libera así al hombre de la duda, facilitándole su comprensión del mundo. Ya no tiene que pensar o reflexionar sobre sí mismo, los otros o el universo, el mito se lo resuelve. Otra de la razón persuasiva es el prestigio que nace de su carácter fundacional y el poder personificado en las figuras encargadas de narrar el mito al resto de la sociedad. También es necesario recordar que el mito está íntimamente ligado a la imagen, según lo define Cassirer, es una emoción convertida en imagen. El poder persuasivo de éstas, de las estructuras míticas, es incuestionable, son figuras ambivalentes, emotivas, que se dirigen al pensamiento del receptor, consiguiendo lo que desean, pues, según los publicistas, no es 
la razón la principal guía de nuestra conducta, sino las emociones y los sentimientos.

El poder de la publicidad ha ido creciendo progresivamente desde su nacimiento hasta la actualidad alcanzando su mayor esplendor hoy. En la era del homo videns la publicidad cobra un valor preponderante en el marco de la persuasión, entendiendo como tal la sociedad teledirigida, miramos para conocer y analizar lo que pasa a nuestro alrededor.

\section{4. ¿Qué es el lujo?}

El lujo es una forma de consumo, se formaliza cuando expresa un valor establecido frente a un tipo de carencia también establecida, y sobrepone un individuo a los demás, creando una diferenciación social que presupone poder. Según afirmaba Coco Chanel: "El lujo es una necesidad que nace donde la necesidad acaba". Estamos ante productos que se distinguen, por ejemplo, en la forma que se conciben y fabrican, en la manera en que se distribuyen y en la relación que establecen las marcas con el cliente.

El lujo es la consecuencia de la meritocracia, es aquello que diferencia a las personas en función de sus méritos. Si alguien quiere elevarse a si mismo a ojos de los demás, tiene en las marcas de lujo unas grandes aliadas. Sin embargo, no es el cliente el que domina la marca, sino al revés. Ello no quiere decir que las marcas de lujo no respeten a sus clientes, se trata simplemente de mantener de alguna manera distancia con el cliente para que la marca conserve su aura de misterio, por tanto vemos que a diferencia de las marcas de gran consumo, las marcas de lujo no hacen publicidad con el ánimo de vender sino con la intención de perpetuar el mito, el misterio y aureola de magia que éstas construyen en torno a las mismas.

Lo que caracteriza a un artículo de lujo es su carácter "innecesario" por lo que debe promocionarse ampliamente para generar el deseo del consumidor. El activo más fuerte que tienen las marcas de lujo son su historia, su tradición y su arte por lo que toda estrategia de comunicación deber preservar estos atributos y mantener una coherencia con el resto de materiales.

Los atributos que identifican a un artículo de lujo son por ejemplo un precio alto, que sea único, escaso (difícil de conseguir), exquisito, glamuroso, de máxima calidad, de artesanía, con distinción, que otorgue estatus y que se relacione con el deseo, la creatividad o el saber hacer... pero yo voy más allá tratando de entender qué es en sí mismo no por sus propiedades.

Los consumidores de lujo son cada vez más selectivos sobre dónde realizar una compra. La mejor forma de que las marcas de lujo sigan teniendo su lugar, es proporcionar experiencias únicas y convincentes. Que el consumidor pueda pagar un producto, ciertamente, es un requisito, pero que desee gastar dinero por obtener ese artículo resulta una motivación distinta. Comentarios como "mi mejor cliente no es el más rico, sino alguien que adora mis productos y ahorra para tenerlos" son frecuentes en estos mercados.

El marketing de los productos de lujo difiere mucho del marketing de un producto normal. El mercado de las marcas de lujo no admite comparaciones entre las marcas, ser una marca verdaderamente única es lo que importa. Es importante que Chanel tenga una personalidad verdaderamente única y atemporal, no que sea mejor 
o peor que Yves Saint Laurent. Para Chanel, el precio no es un problema, porque la gente seguirá comprando sus productos. Se realizó un estudio, tomando productos de Chanel y de otras marcas quitándoles las etiquetas y logos. Al poner la etiqueta de Chanel sobre un objeto, rápidamente la gente estaba dispuesta a pagar mucho más, lo que fuera en algunos casos.

Para las marcas de lujo, la exclusividad ha sido siempre una pieza clave en su éxito. En el mercado de lujo hoy, convencer a los clientes de que compren un producto no es suficiente, hay que convencerles que se unan a unos valores, a una experiencia y a una historia. Si no buscamos una experiencia que nos lleve a la emoción, que toque nuestra fibra sensible, será difícil que la marca pueda resistir. El saber hacer distintivo y la exclusividad del producto son condiciones necesarias para competir en este mercado, ya que hemos visto que en este negocio mirar a la competencia no es un fin.

Las marcas de lujo satisfacen a un consumidor que puede comprar casi cualquier cosa que ellos quieran debido a su alto nivel adquisitivo, por eso las experiencias deben ser vividas dentro de una historia exclusiva. Aunque las marcas de lujo deben ir más allá y buscar ser reconocidas también por aquellos que nunca comprarán sus productos. Si no lo hacen así, perderían su valor como marcas, se trata de ser reconocidas por todo el mundo, pero sin estar al alcance de todo el mundo, la reputación y la tradición cuentan y hay que difundirlas y alimentarlas.

Las marcas de lujo deben aceptar el hecho de que sus productos principales son esquivos, efímeros y que sus productos son medios físicos sólo a través de los cuales, los consumidores pueden alcanzar esos sentimientos, por lo tanto una marca de lujo debe determinar su valor emocional implementando acciones que expresen y atraigan la emoción de sus clientes.

Lo que buscan los consumidores al adquirir un artículo de lujo, a veces más allá del lujo, y las empresas que se dedican a estos productos, juegan con sueños y emociones. Son empresas que como hemos dicho, atesoran conceptos como calidad, innovación, historia, tradición y nostalgia. Cuando se unen todos estos factores la marca se convierte en mito y genera un deseo inconfesable. Se convierten en productos únicos, sin sustitutos posibles.

\section{Casos concretos de artículos de lujo que usan los mitos en sus campañas para impactar más en el mensaje}

Burberry, la multinacional británica, por ejemplo ha incrementado sus ingresos, en los últimos años al incorporar estrategias experienciales, la experiencia de una marca de lujo no es tan sólo ofrecer un producto de lujo (que ya se presupone) sino ofrecer una experiencia relacionada con el producto que vende, que nunca defrauda, los consumidores son leales a Burberry porque quieren sentirse auténticos y atemporales.

Al hablar de marcas de lujo, el engagement o el arte de crear una relación de amor incondicional hacia una marca, tiene que ver mucho con la historia, al fin y al cabo es lo que vende la historia. Tiffany \& Co también incrementó sus ventas después que el público y la prensa tuvieran buen crítica del microsite del "Amor verdadero" y la aplicación del "anillo de compromiso", comunicaron una historia poderosa de marca asociadas con el valor fundamental de la misma, el amor, los clientes frecuentan Tiffany para sentir de otra manera "el amor". 
Son empresas que no tienen competencia, en general, lo que les permite cobrar lo que quieran por sus productos, por ejemplo Hermès, ha subido el precio de sus artículos un 9\% sin importarles la actual situación económica, el cliente sabe que es el mejor y eso otorga muchas ventajas. Conseguir este estatus es una tarea ardua y todavía más difícil e mantenerlo. Por ejemplo los bolsos de Hermès el modelo Kelly y Biskin tienen listas de espera de más de cinco años y precios que van desde los 10.000 euros, para el modelo más sencillo, hasta más de 45.000 para el que está elaborado con cocodrilo. Pues bien, el prestigio se consigue desde la confección, que realiza siempre el mismo artesano, y que dura más de 20 horas para cada bolso. Además si el cliente raya el bolso lo puede devolver al mismo artesano que se lo arreglará sin coste adicional, son pequeños detalles que hacen grande el producto.

Hermès como sabemos es una marca de maletas, bolsos, cinturones... En la mitología griega Hermès es el dios protector de los caminantes y viajeros. Hijo del dios Zeus y de Malaya, la hija de Titán Atlas. Como especial servidor y correo de Zeùs, Hermès tenía un sombrero y sandalias aladas y llevaba un caduceo de oro, o varita mágica con serpientes enrolladas y alas en la parte superior. Guiaba a las almas de los muertes hacia el submundo y se creía poderes mágicos sobre el sueño. También era el dios del comercio en general, protector de comerciantes y pastores. Como divinidad de los atletas, protegía los gimnasios y los estudios, y se le consideraba responsable tanto de la buena suerte como de la abundancia. Al igual que todos los demás dioses, Hermès era inmortal, invencible y poseía superfuerza. Era el ser más rápido de todos los que moraban el Olimpo, este poder llegó de las botas con alas.

No tengo duda que al pensar el nombre de la marca esta inspiración mitológica ha jugado un papel fundamental y ha hecho que el éxito y la exclusividad sea más notoria, con todas estas connotaciones comprar este producto va más allá del lujo.

Obviamente si Hermès aumentara su producción no podría ofrecer esos estándares de calidad. Quizás esa exclusividad es lo que origina que estas empresas se benefician de las crisis económicas. En estos tiempos, los inversores buscan valores seguros, que no se deprecien. Y la verdad es que existen pocas cosas más seguras que un mito. En concreto Hermès, su facturación creció un $60 \%$ los tres años posteriores a la crisis del 2007. A pesar de este incremento, la firma gala nunca perderá el concepto de exclusividad. Para comprobarlo basta con leer esta declaración del presidente Patrick Thomas:" hay una parte del mundo que se aprovecha de la abundancia, de la ostentación del glamour. Hay otra que está concentrada en la delicadeza, y en fabricar objetos hermosos. Hermès no quiere ser parte de ese mundo financiero que arruina empresas y trata con personas como si fueran materiales sin tratar, Si usted me dice que tengo que doblar mis resultados, lo podría hacer mañana, pero Hermès dejaría de existir en 5 años". Por sus palabras se desprende que estas firmas artesanales compiten en la otra liga. En una basada en la excelencia, que nunca se vendería por dinero.

Otro caso Volvo significa "rodando" en latín, el viejo símbolo en la insignia (círculo con la flecha) proviene de la mitología griega y simboliza al dios Marte, la entidad divina de la guerra, el escudo y la lanza, símbolo de fuerza y resistencia, cuyo mensaje sería potenciar la fuerza o la potencia de estos coches sería el mensaje.

Versace, por ejemplo se ha agarrado a un logotipo que representa la cabeza de una medusa, la historia cuenta que era una mujer que se transformó en un monstruo después de ofender a los dioses. El mito dice que era una sacerdotista de Atenea que fue violada en el templo por Poseidón. Atenea vio eso como un gran sacrilegio así 
que transformó el cabello de Medusa, que había sido su tributo más preciado, en serpientes venenosas. Según cuenta la historia, todo aquel que la miraba se convertía en piedra. Y eso era lo que el diseñador quiso plasmar, es decir que cada vez que alguien viese sus diseños se quedase de piedra. Sus diseños se basan en la Grecia Antigua. Todo el que se enamora de Medusa no puede huir de ella. La insignia de Medusa con la llave griega es una alusión al mundo clásico vinculado con la clase y la riqueza. Muchas de las colecciones del diseñador aluden a la historia clásica, y casi siempre incluyen vestidos tipo diosa y motivos griegos. La Medusa es símbolo de la moda Versace, quien siempre quiso que sus diseños invocaran a una diosa, a una mujer poderosa.

En muchos casos las marcas de lujo no crean productos perfectos, son sus pequeños fallos los que las convierten realmente en únicas, es el caso de la mítica marca Ferrari, cuyos coches son la antítesis de una conducción sencilla, tranquila y silenciosa. Ferrari símbolo de velocidad, gloria y competitividad fue creado por Enzo Ferrari.

Y así podríamos seguir hablando de muchos productos de lujo en todos los sectores, automóviles, ropa, viajes, joyas, perfumes...que se han inspirado en mitos, por lo que podemos deducir que no es casualidad que se usen los mitos como un recurso de la publicidad.

\section{La publicidad sí sabe de crisis, pero ha sabido adaptarse gracias a la globalización}

En general, la crisis afecta a la práctica publicitaria, parece que una primera impresión, se está forjando el mito de que la publicidad ya no funciona, la idea que está en el ambiente es que existe una menor confianza en la publicidad, y que la publicidad deja de ser todopoderosa.

Pero aunque el anunciante reduzca su inversión publicitaria, todavía no se ha llegado a la alarma y se conserva la calma, la situación es de cautela, no crispada, en la medida en que la publicidad refleja a la sociedad, no ha llegado a plasmar la crisis.

Por lo tanto aunque en general es obvio que la crisis afecta y ha afectado a los parámetros económicos de las empresas de publicidad, lo que está claro es que se están transformando las formas de observar el propio fenómeno de la publicidad. Pero aún con todo, la publicidad sigue siendo la forma más efectiva para generar la fidelidad hacia una marca que respalda un producto de calidad, y por eso el reto está en ser más exigentes, más creativos, más cercanos al consumidor, más estimados, y es aquí donde el mito cobra una especial relevancia, al tender gastar los consumidores más en experiencias que en los propios objetos.

Por esto se podría hablar de una publicidad mítica que como hemos dicho, mediante historias imaginadas da al producto sentido y valor, por eso los profesionales publicitarios recurren a leyendas, héroes, símbolos casi universales, ya que los mitos tienen un lenguaje internacional, y quitando algunas excepciones, todo el mundo les entendemos igual. Los mitos ayudan a no entender de crisis debido a su lenguaje universal.

Tradicionalmente los consumidores del lujo eran un grupo cerrado, formado por occidentales y japoneses, fue la era del lujo exclusivo, grandes seguidores de una marca que profesaban fidelidad, gente rica muy rica, de la que por cierto, cada vez 
hay más gente en el mundo. Pero con la explosión del sector a partir de mediados de los años ochenta se generaliza la aspiración a lo lujoso y aparece un nuevo perfil. Los mercados emergentes (China, India y Rusia) se expanden y llegan al lujo dispuestos a comprarlo todo, o en los países árabes, casi no saben qué hacer con el dinero. Gente que compra seda, perfumes, cosméticos, marroquinería u otros productos ostentosos de forma puntual, están de excursión en el mundo del lujo.

El consumo en China, para la economía globalizada tiene un papel clave. Según las estadísticas actuales China ha reemplazo a Japón para convertirse en el mayor consumidor de bienes de lujo. En muchas ocasiones usan el dragón para la promoción de sus productos, por ejemplo marcas de lujo chinas en las que aparece el símbolo del dragón son Rolls-Royce, ST Dupont, Salvatore Ferrogamo, Versache... ya que el dragón es un animal mitológico para los chinos, además de influir a nivel personal y profesional en sus decisiones. Los consumidores chinos son de los pocos que antes de comprar, valoran, investigan, se informan..., eso en realidad es ser un experto comprador de lujo.

\section{Conclusiones}

Vemos por tanto cómo algo que debería ser racional como es el consumo, algo lógico, contar con una renta determinada y contar con que los bienes tienen un precio de mercado, esta actuación se convierte totalmente en ilógica e irracional, cuando accede la emoción y los sentimientos.

Una vez estudiado la importancia de los mitos para comprender el mundo contemporáneo a través de la publicidad en el consumo, y en concreto en algún caso de artículos de lujo, vemos la necesidad de los mitos para el hombre, el ser humano más que nunca necesita referencias que le hagan que su vida tenga más sentido, en nuestro caso a través de los productos que consume.

Vemos también que los mitos se adaptan a los tiempos, no mueren, aparecen unos, quedan relegados otros, pero siempre están presentes, ayudan a reforzar los mensajes publicitarios por todo el contenido emocional que hay detrás de ellos, los mitos hacen que los mensajes cojan más fuerza y sobrevivan más en el tiempo., corroborándose esta afirmación con los artículos de lujo.

Los artículos de lujo son los productos en los que más impacto tienen los mitos por lo que busca el consumidor cuando los compra, en épocas de crisis son especialmente estos artículos los que menos se resienten, por el público tan especial al que van dirigidos y lo exigentes que son ya que no buscan sólo comprar ese artículo, en muchos casos es hasta un estilo de vida . Los consumidores de productos de lujo buscan diferenciarse del resto, continuamente surgen marcas nuevas, algunas de ellas son simplemente fenómenos de temporada, pero mucho cuidado que pueden quitar muchos clientes a las marcas de siempre y por ello deben estar preparadas,

Por todo esto, hay que seguir reinventándose en todos los aspectos, el mercado del lujo puede sufrir un giro. Datos recientes reflejan que las compañías del sector mundial del lujo presentan un cambio de tendencia. Una vez superada, además holgadamente, la facturación durante la crisis crediticia mundial, vemos como los problemas geopolíticos a corto plazo pueden pasarles factura. En el presente año 2017 habrá cambios, es un negocio en el cual el consumidor es muy exigente y en la 
actualidad existen problemas como China, cuyo crecimiento es este sector ya no es tan frenético, además si añadimos los atentados seguidos sufridos en Europa, principalmente en Paris, ha hecho que la llegada de turistas chinos a Francia en el último año hayan caído, siendo París la meca de las marcas.

\section{Bibliografía}

Baudrillard, J (1972): Crítica de la economía política del signo. México, siglo XXI

Baudrillard, J (2009): La sociedad de consumo. Sus mitos, sus estructuras. Madrid: Siglo XXI.

Cassirer, E (1992): Antropología filosófica. Ed. FCE. México

Costa, J (1993): Reiventar la publicidad. Reflexiones desde las ciencias sociales. Madrid, Fundesco.

Cutolo, G (2005): Lujo y diseño. Barcelona. Santa \&Cole

Foster, Hal (2002): Diseño y delito (y otras diatribas). Madrid, Akal

Haug, W (1989): Publicidad y Consumo. Crítica de la estética de mercancías. México, Fondo de Cultura Económica.

Herreros, M (1994): La contraprogramación en televisión desde la óptica publicitaria, en Revista Universitaria de Publicidad y Relaciones Públicas.

Lipovetsky, G (2004): El lujo eterno. De la era de lo sagrado al tiempo de las marcas. Barcelona, Anagrama.

Malinowski, B (1994): El mito en la psicología primitiva. Magia, ciencia, religión. Ed. Ariel, Barcelona.

Pérez Tornero, J (1992): La seducción de la opulencia. Publicidad, moda y consumo. Barcelona. Paidós.

Ritzer, G (2000): El encanto de un mundo desencantado. Barcelona, Ariel.

Simmel, G (1997): Filosofía del dinero. Traducido por Ramón Garcia. Madrid. Instituto de Estudios Políticos.

Thorstein B.Veblen. Prolo de Carlos Mellizo (2008): Teoría de la clase ociosa. Alianza Editorial. Madrid 